\title{
T lymphocytes and silica-induced pulmonary inflammation and fibrosis in mice
}

\author{
Naohito Suzuki, Ken Ohta, Tadashi Horiuchi, Hajime Takizawa, Takashi Ueda, Maya \\ Kuwabara, Junji Shiga, Koji Ito
}

\begin{abstract}
Background - Silica-induced pulmonary inflammation and fibrosis in animals provides a good model for chronic pulmonary inflammation and fibrosis. Although lymphocytes are implicated in the pathogenesis of pulmonary fibrosis, experimental models using silica-treated athymic nude mice have not been successful in showing the fibrogenic mechanism regulated by $T$ cells. The aim of this study was to re-evaluate the role of $T$ lymphocytes in the development of silicosis by comparing the response to silica administration of nude athymic mutants with that of euthymic animals.
\end{abstract}

Methods - Suspensions of silica particles were transnasally administered to nude athymic mice (Balb/c nu/nu) as well as to their euthymic littermates (Balb/c nu/t). The degree of pulmonary inflammation and fibrosis was assessed on days 14,28 , and 56 based upon histological observation, analysis of collagen deposition in the lungs, and analysis of the cellular constituent, protein, and phospholipid content in the bronchoalveolar lavage fluid.

Results - Histologically, athymic mice developed less severe interstitial pneumonitis than euthymic mice. In euthymic mice the lung hydroxyproline content increased with time after silica administration from $6.48(0.38) \mu g$ hydroxyproline/mg dry lung weight on day 0 to $8.87(0.41) \mu \mathrm{g} / \mathrm{mg}$ on day 56 . A gradual increase in lung hydroxyproline content was also observed in athymic mice but the increase was significantly smaller than in euthymic mice (6.63 (0.43) $\mu \mathrm{g} / \mathrm{mg}$ on day 0 , $7.90(0.19) \mu \mathrm{g} / \mathrm{mg}$ on day 56). Administration of silica resulted in an increase in the number of macrophages and neutrophils and in the total protein and phospholipid content of the bronchoalveolar lavage (BAL) fluid in both mouse strains. No significant difference was detected between athymic and euthymic mice in the numbers of macrophages, but the increase in neutrophils in the BAL fluid of athymic mice was significantly smaller than in euthymic mice on days 14 and 56 . The total protein and phospholipid content of the BAL fluid from athymic mice was lower than that from euthymic mice.

Conclusions - T lymphocytes appear to be involved in the pathogenesis of silicainduced pneumonitis. Since pulmonary fibrosis develops even in nude athymic mice, $T$ cells do not seem to play a primary part in the fibrogenic response but they regulate, at least to some extent, the response of inflammatory cells and fibrogenesis of the lung.

(Thorax 1996;51:1036-1042)

Keywords: athymic mice, T lymphocytes, silicosis, pulmonary fibrosis.

The cellular mechanisms in the development of pulmonary fibrosis have been extensively studied but are poorly elucidated. Many investigators suggest that lymphocytes, especially $\mathrm{T}$ lymphocytes, play an important part in the response to fibrogenetic stimuli. ${ }^{12}$ The ability of $\mathrm{T}$ cells to modulate fibroblast proliferation has been established in vitro. ${ }^{34}$ Many animal models have been employed to analyse the pathogenesis of fibrosis in vivo, and nude athymic mice have been generally used to clarify the role of $\mathrm{T}$ cells. In bleomycininduced pulmonary fibrosis, nude mice have reduced collagen deposition in the lung. ${ }^{5}$ The involvement of $\mathrm{T}$ lymphocytes in interstitial pneumonitis induced by pepleomycin ${ }^{6}$ and by trehalose ${ }^{7}$ has also been reported in athymic nude mice.

Experimental silicosis in animals is another good and well documented model for the study of the mechanisms of chronic pulmonary inflammation and fibrosis. ${ }^{8}$ Activated macrophages and cytokines released from them are widely accepted as primary factors in the pathogenesis of silicosis. ${ }^{9-12}$ However, histological assessments of the pulmonary interstitium and analyses of bronchoalveolar lavage (BAL) fluid in silica-treated animals have suggested that lymphocytes are also activated in silicosis, ${ }^{13}$ and that their interaction with activated macrophages may be important in the control mechanism of chronic pulmonary inflammation and the fibrogenic response. ${ }^{1416}$ Nonetheless, the involvement of $\mathrm{T}$ lymphocytes in silica-induced pulmonary fibrosis has not been clearly elucidated in nude athymic mice. ${ }^{17}$ Hubbard reported that neither $\mathrm{T}$ cells nor the cells they influence affect the amount of collagen deposition elicited by silica. ${ }^{18}$

Regulation of the fibrotic response in the airways by $T$ cells has recently been reported. ${ }^{19} 20$ Interactions between lymphocytes and macrophages have been well established, ${ }^{21-23}$ and regulation of cytokine production in macrophages by products from activated $T$ cells is widely reported. ${ }^{24-26} \mathrm{We}$ have therefore reevaluated the role of $\mathrm{T}$ lymphocytes in the development of silicosis by comparing the response to silica administration of nude 
athymic mutants (Balb/c nu/nu) with that of euthymic littermates (Balb/c nu/t). The degree of pulmonary inflammation and fibrosis was assessed by histological examination and chemical analysis of collagen deposition. The degree of pulmonary inflammation was also assessed by measuring the protein and phospholipid content of the BAL fluid, since many investigators have reported that a significant increase in the protein and phospholipid content of the BAL fluid is a characteristic response to the administration of silica. ${ }^{27-29}$ Our results suggest that $T$ lymphocytes regulate silica-induced pulmonary inflammation and fibrosis although they do not play a pivotal part in the pathogenesis of the disease.

\section{Methods}

ANIMALS

Athymic nude mice (Balb/c nu/nu) and their euthymic littermates (Balb/c nu/+) were purchased from Shizuoka Laboratory Animal Center (Shizuoka, Japan). All animals were five week old males. They were kept in sterile, filter-capped cages and fed with sterile food and water in a specific pathogen-free room designed for nude mice at the Division of Animal Research, Faculty of Medicine, University of Tokyo.

ADMINISTRATION OF SILICA

Silica suspension was administered to mice according to the method used in our previous study ${ }^{30}$ with a slight modification. Briefly, silica particles (Wako Chemical Drugs, Tokyo, Japan) were suspended in physiological saline and ultrasonicated prior to use. The suspension was transnasally administered to each mouse $(1.5 \mathrm{mg} / \mathrm{g}$ body weight $)$ under anaesthesia with ether on days 0 and 1 . Control mice were administered saline on the same days. On days 14,28 , and 56 the animals were anaesthetised, peritoneally injected with heparin, and sacrificed by cutting the abdominal aorta. The mice were divided into three groups: one for histological examination, one for lung hydroxyproline assay, and another for BAL fluid analysis. The number of mice in each group was 5-7 for each experimental day.

HISTOLOGICAL EXAMINATION

The lungs were fixed in $10 \%$ formalin under constant pressure $\left(10 \mathrm{~cm} \mathrm{H}_{2} \mathrm{O}\right)$ overnight. Sample sections were taken from the largest lung plane and stained with haematoxylin and eosin. Lung lesions were examined under an optical microscope with magnification from $10 \times$ to $400 \times$. The following modification of the method used by Rossi and colleagues ${ }^{31} 32$ was employed to score the lesions: 0 , no inflammatory cell infiltration nor alveolar thickening; 1, sporadic, minute foci of inflammatory cell infiltration and alveolar thickening (presence of lesions involving less than $10 \%$ of the lung); 2 , mild interstitial inflammation (lesions involving $10 \%$ to $30 \%$ of the lung); 3 , considerable interstitial inflammation and/or occasional presence of silicotic nodules (lesions involving $30 \%$ to $50 \%$ of the lung); 4 , diffuse, severe interstitial pneumonitis with scattered silicotic nodules (lesions involving more than $50 \%$ of the lung). The extent of the lesions was evaluated by two independent examiners who were blinded to the experimental group.

\section{LUNG INDICES}

In order to quantify the pulmonary inflammation responses further, we calculated lung indices by the method described by Allen and coworkers: ${ }^{334}$

\section{Lung index $=$ \\ (lung weight/body weight) animal in question \\ (lung weight/body weight) control animal}

Our previous studies have shown that the lung indices correlate with the histological scores in the murine hypersensitivity pneumonitis model. $^{35}$

\section{HYDROXYPROLINE ASSAY}

The removed lung was washed in physiological saline and freeze dried at $-50^{\circ} \mathrm{C}$. The dried whole lung was hydrolysed in $6 \mathrm{~N} \mathrm{HCl}$ at $110^{\circ} \mathrm{C}$ for 18 hours. The solution was neutralised with $\mathrm{NaOH}$ and centrifuged at $1000 \mathrm{~g}$ for 10 minutes. The hydroxyproline content of each sample was determined using the assay of Woessner $^{36}$ and the mean value of the triplicates was employed. Since athymic mice are smaller in body weight than euthymic mice of the same age, the increase in hydroxyproline content of the whole lung relative to body weight was calculated as a lung hydroxyproline index defined as follows, based upon a lung index:

Lung hydroxyproline index $=$

(lung hydroxyproline content/body weight) animal in question $_{\text {na }}$ (lung hydroxyproline content/body weight) control animal

A lung index of $>1.0$ means that there is an increase in lung hydroxyproline content relative to body weight.

ANALYSIS OF BAL FLUID

In order to assess pulmonary inflammation, the constituents of the BAL fluid were also analysed. ${ }^{37}$ Bronchoalveolar lavage was repeated by injecting $0.6 \mathrm{ml}$ physiological saline intratracheally until $5 \mathrm{ml}$ of BAL fluid was collected from each mouse. Cells in the BAL fluid were collected by centrifuging at $400 \mathrm{~g}$ for 10 minutes and resuspended in $1 \mathrm{ml}$ of calciumand magnesium-free Hank's balanced salt solution (GIBCO). A portion of the cell suspension was stained with trypan blue for total cell counting. After collecting cells onto a glass slide in a cytocentrifuge (Shandon Southern Products, Cheshire, UK) the cell differentials were analysed by staining with Diff-Quick (HARLECO, Philadelphia, Pennsylvania, USA). For each smear 500 cells were analysed morphologically. The total protein content of the cell-free BAL fluid supernatant was measured using BCA Protein Assay kit (PIERCE, Rockford, Illinois, USA). Each sample was analysed in triplicate and the mean value was used as the BAL fluid protein content of each mouse expressed as $\mu \mathrm{g}$ protein $/ \mathrm{ml}$ BAL fluid.

Lipids in the cell-free BAL fluid were extracted with chloroform and methanol after freeze drying. ${ }^{38}$ The phospholipid content of 
the extracted lipids was determined by the microphosphorus method of Rouser et $a l^{99}$ and the mean value of the triplicate samples was used as the phospholipid content of the BAL fluid of each mouse expressed as nmol phosphate residues/ml BAL fluid.

\section{STATISTICAL ANALYSIS}

The data are expressed as mean (SE) values. Statistical analyses included one-way analysis of variance and Student's $t$ test of unpaired data. To analyse the difference in the histological scores among different experimental groups a non-parametric test (Kruskal-Wallis) was used because the data are not normally distributed. Differences between means were regarded as significant when $\mathrm{p}<0.05$.

\section{Results}

PULMONARY LESIONS

Figure 1 demonstrates the pulmonary lesions induced by silica in normal (A and B) and nude (C and $D$ ) athymic mice on day 56. Interstitial pneumonitis developed in both strains but athymic mutants had milder lesions. Thickening of alveolar septa and formation of granulomas was considerable and widespread in the lungs of silica-treated euthymic mice. In athymic mice alveolar thickening was generally mild and granulomas were small and sparsely scattered, although severe lesions were observed locally in the lungs of some animals. The cells infiltrating into the granulomas were mostly mononuclear in both strains. The degree of the lesions showed considerable variability from mouse to mouse, being almost fully developed by day 14 in some and only mild in others. On average, the pathological findings on days 14 and 28 in silica-treated mice were similar to those on day 56 . Lungs from $\mathrm{nu} /+$ and $\mathrm{nu} / \mathrm{nu}$ mice administered with saline (control) showed almost no abnormalities (not shown).

A summary of the pathological findings, quantified as histological scores, is shown in fig 2A. Before administration of silica (day 0 ) no significant difference was observed between
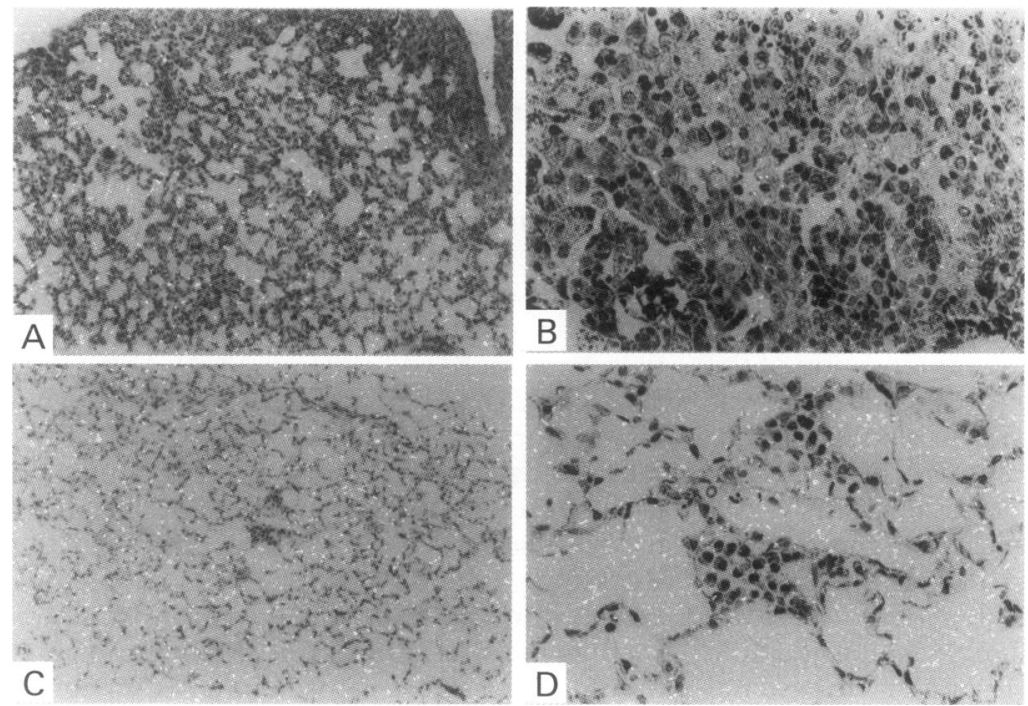

Figure 1 Interstitial pneumonitis induced by silica in $(A)$ and $(B)$ lungs from euthymic mice $(n u /+)$ and $(C)$ and $(D)$ lungs from athymic mice (nu/nu). Stain: haematoxylin and eosin. Magnification: $\times 40$ ( $A$ and $C), \times 100(B$ and $D)$. euthymic and athymic animals. Administration of silica resulted in a significant increase in the histological scores compared with untreated mice ( $\mathrm{p}<0.01$, Kruskal-Wallis rank sum test) in both euthymic and athymic mice, with the mean score in athymic mice being significantly smaller than that in euthymic mice $(p<0.05)$ on all days investigated. Scores in silica-treated euthymic mice showed a slight trend to increase with time after silica administration, but the differences in the mean scores and variance among different days were not statistically significant. Analysis of lung indices showed increases in silica-treated mice which corresponded with the histological scores (fig $2 B$ ). The increase was always greater in euthymic nu/+ mice than in athymic nu/nu mice, and the difference between the two strains was statistically significant $(p<0.05)$ on all days investigated after silica treatment. Saline induced no significant changes in histological scores and lung indices in either euthymic or athymic mice (data not shown).
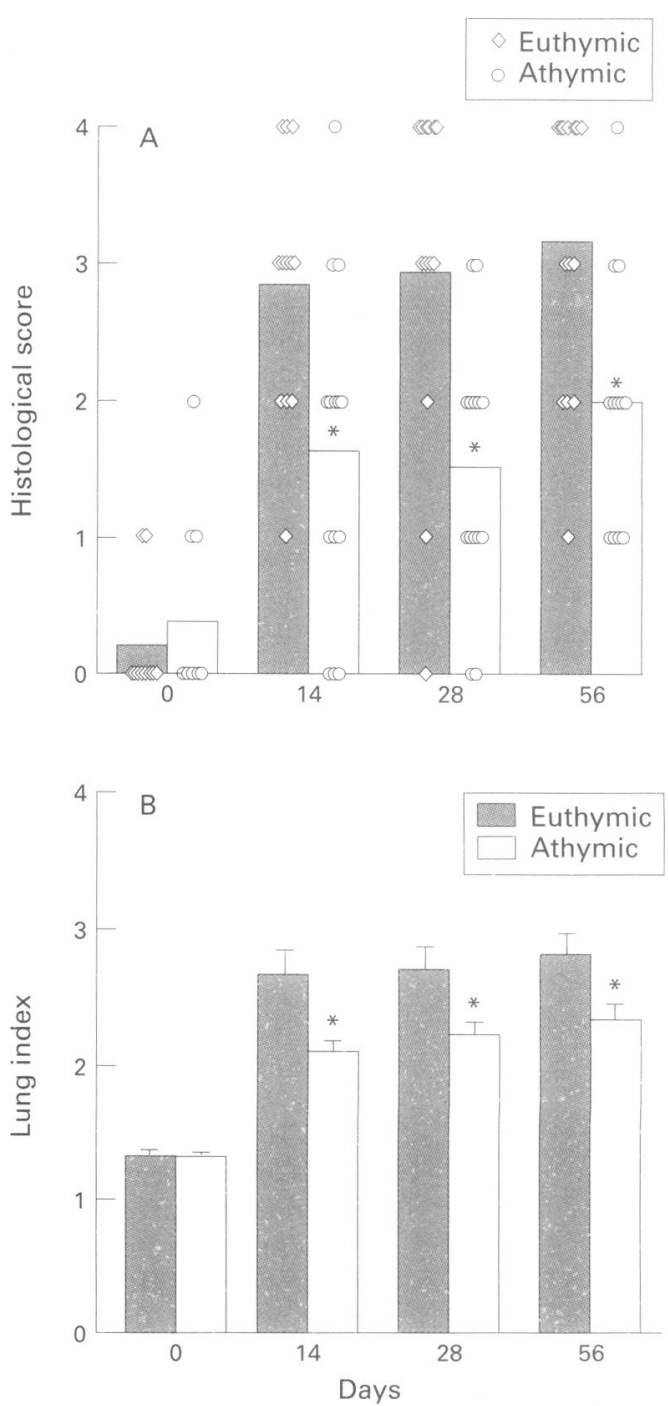

Figure 2 (A) Histological scores and (B) lung indices of euthymic and athymic mice. Data are presented as mean (SE) of 5-12 animals. Values on day 0 correspond to untreated mice. Data from control mice (treated with saline) on days 14,28, and 56 are not shown as no significant changes from untreated mice were investigated. $\star_{p}<0.05$ compared with euthymic mice. 
Table 1 Mean (SE) hydoxyproline content per dry lung weight $(\mu \mathrm{g} / \mathrm{mg})$. Control mice are treated with saline. Values on day 0 correspond to the mice before saline/silica treatment

\begin{tabular}{lll}
\hline & $n u /+$ & $n u / n u$ \\
\hline Day 0 & $6.48(0.38)(\mathrm{n}=5)$ & $6.63(0.43)(\mathrm{n}=5)$ \\
$\begin{array}{l}\text { Day 14 } \\
\quad \text { Control }\end{array}$ & $6.40(0.45)(\mathrm{n}=7)$ & $6.57(0.41)(\mathrm{n}=5)$ \\
$\quad$ Silica & $6.17(0.40)(\mathrm{n}=5)$ & $7.01(0.38)(\mathrm{n}=6)$ \\
Day 28 & & \\
$\quad$ Control & $7.04(0.33)(\mathrm{n}=7)$ & $6.86(0.50)(\mathrm{n}=5)$ \\
$\quad$ Silica & $6.78(0.52)(\mathrm{n}=7)$ & $7.42(0.46)(\mathrm{n}=5)$ \\
Day 56 & & \\
$\quad$ Control & $7.00(0.35)(\mathrm{n}=6)$ & $6.98(0.38)(\mathrm{n}=5)$ \\
$\quad$ Silica & $8.87(0.41) \dagger(\mathrm{n}=5)$ & $7.90(0.19)^{\star}(\mathrm{n}=6)$ \\
\hline
\end{tabular}

$\dagger p<0.01$ compared with control mice on the same experiment day.

${ }^{\star} \mathrm{p}<0.05$ compared with $\mathrm{nu} /+$ mice on the same experiment day.

PHYDROXYPROLINE CONCENTRATION

The hydroxyproline content of the whole lung from euthymic mice showed a steady and significant increase after treatment with silica (fig 3A). Although an increase in the hydroxyproline content of the lung was also observed in athymic mice, it was significantly smaller than in euthymic mice. The difference between euthymic and athymic mice became greater as time passed after administration of silica. On

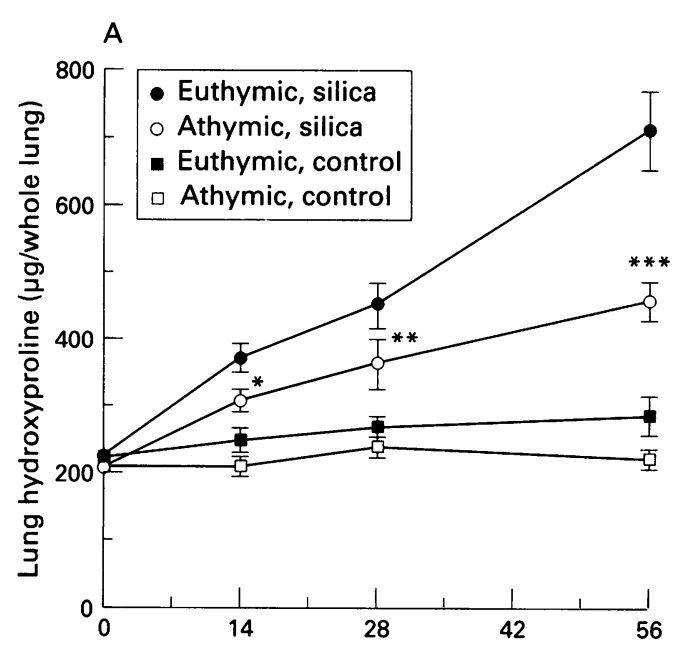

B

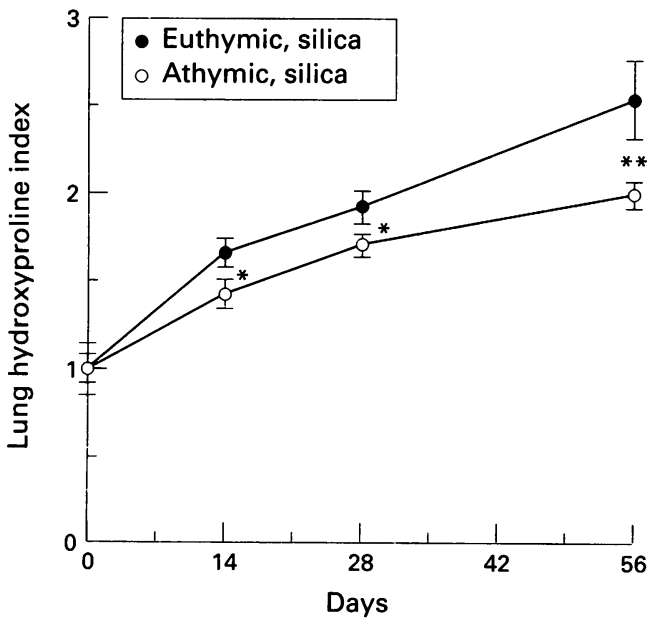

Figure 3 (A) Whole lung hydroxyproline content after administration of silica suspension or saline (control) and (B) hydroxyproline content in the lung corrected for difference in body weight. Values on day 0 correspond to untreated mice. Data are presented as mean (SE) of 5-9 animals. ${ }^{*} p<0.05,{ }^{*} p<0.01,{ }^{*}{ }_{p}<0.001$ compared with euthymic mice. day 56 the lungs from euthymic mice showed more than 1.5 times the hydroxyproline content of lungs from athymic mice. The hydroxyproline content of the lungs from saline-treated mice increased with age, possibly reflecting the growth of mice.

Since euthymic and athymic mice differ in body weight, lung hydroxyproline indices which represent the hydroxyproline content in the lung relative to body weight - were evaluated and were also found to increase after the administration of silica (fig 3B), the increase being significantly smaller in athymic mice than in euthymic mice. This indicates that the difference in the increase in lung hydroxyproline content between athymic and euthymic mice cannot be ascribed to the difference in body weight.

We also evaluated the hydroxyproline content per dry lung weight (table 1). On day 56 a significant increase in this index was observed
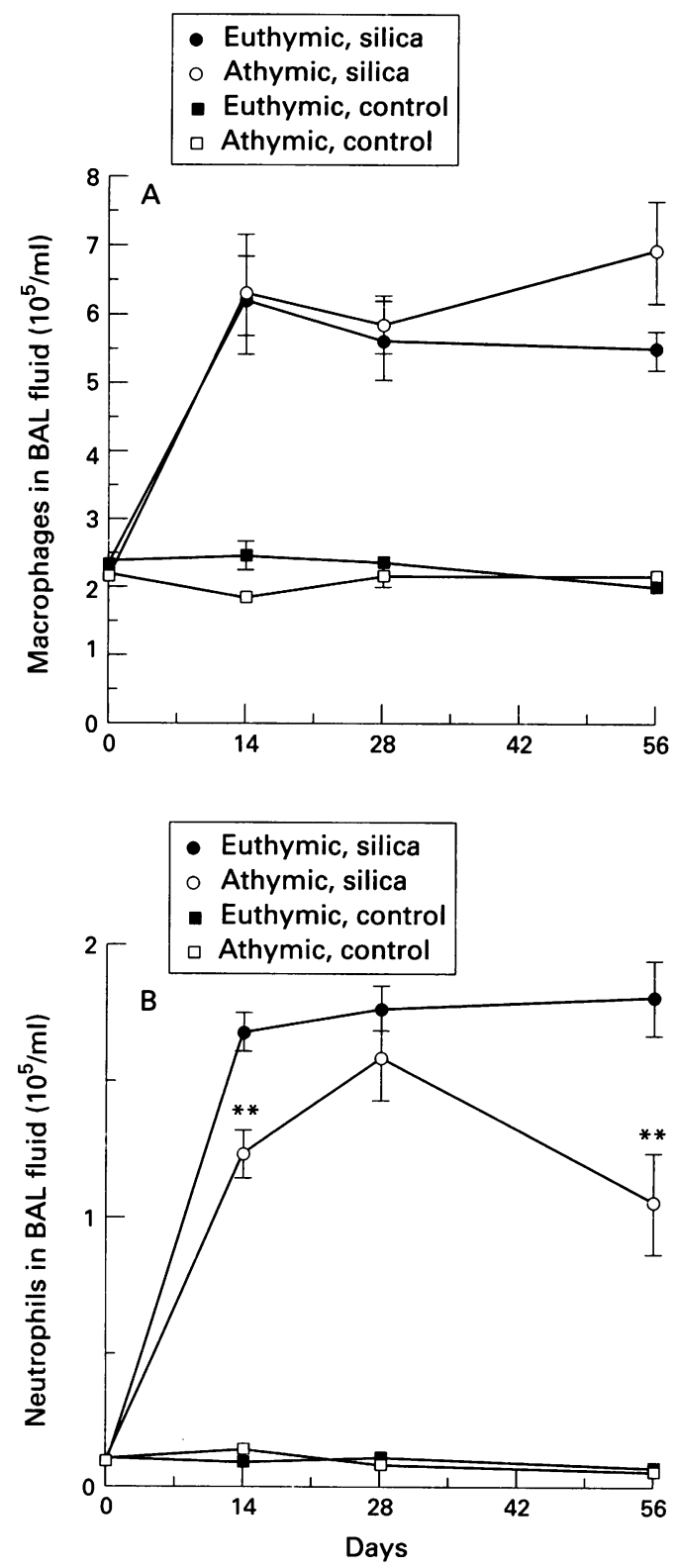

Figure 4 Changes in the numbers of $(A)$ macrophages and $(B)$ neutrophils in the BAL fluid. Values on day 0 correspond to untreated mice. Data are presented as mean (SE) of 5-9 animals. ${ }^{*} p<0.01$ compared with euthymic mice. 


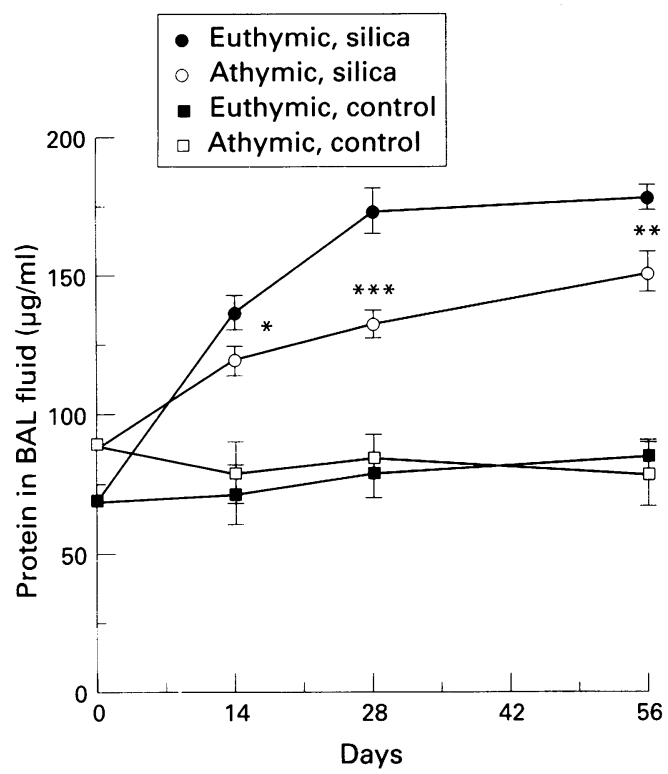

Figure 5 Changes in total protein content of the cell-free $B A L$ fluid after administration of silica suspension or saline (control). Data are presented as mean (SE) of 5-9 animals. Values on day 0 correspond to untreated mice. ${ }_{*} p<0.05,{ }^{\star *} p<0.01,{ }^{\star \star *} p<0.001$ compared with euthymic mice.

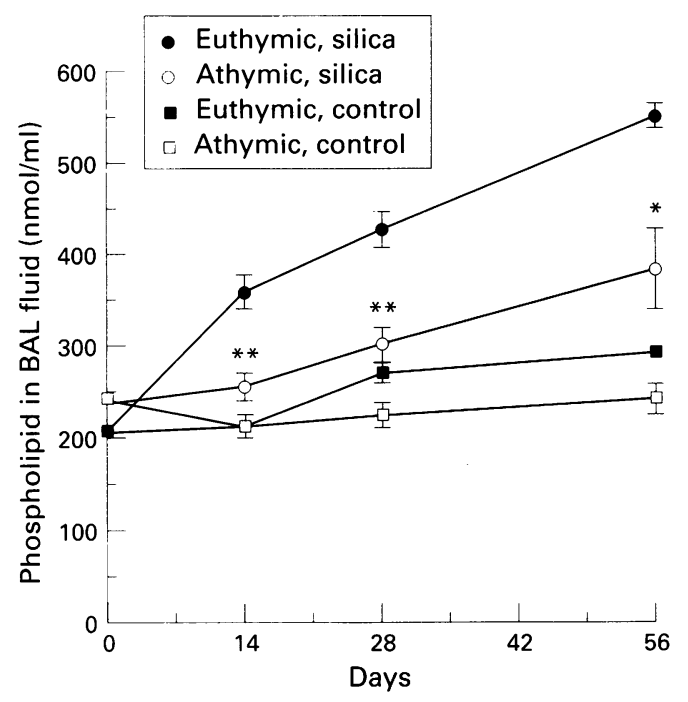

Figure 6 Changes in phospholipid content of the cell-free $B A L$ fluid after administration of silica suspension or saline (control). Data are presented as mean (SE) of 5-9 animals. Values on day 0 correspond to untreated mice. ${ }^{\star} p<0.05,{ }^{\star} p<0.01$ compared with euthymic mice.

in silica-treated euthymic mice compared with control mice $(p<0.01)$. Lungs from nude athymic mice administered silica also showed an increase, but the difference from control animals was not statistically significant $(\mathrm{p}=$ $0.06)$. The average hydroxyproline content/dry lung weight in silica-treated athymic mice was significantly smaller than that of silica-treated euthymic mice $(\mathrm{p}<0.05)$. On days 14 and 28 , however, we could not detect significant differences between athymic and euthymic mice, nor between silica-treated and saline-treated mice.

MARKERS OF LUNG INFLAMMATION

Silica administration induced a significant increase in the number of macrophages and neutrophils in the BAL fluid, both in euthymic and athymic mice (fig 4 ). There was no significant difference in the number of macrophages between the two strains. Athymic mice showed a smaller increase in the number of neutrophils in the BAL fluid than euthymic mice on days 14 and 56, but on day 28 the difference was not significant.

The degree of pulmonary inflammation was also assessed by analysing the protein content of the BAL fluid. As shown in fig 5 , the protein content of the BAL fluid from silica-treated mice increased, with a significant attenuation of the increase in athymic mice compared with euthymic mice. The attenuation was most obvious on day 28 . On day 56 the protein content of the BAL fluid from silica-treated nu/+ mice remained at a similar level to that on day 28 , while that from $\mathrm{nu} / \mathrm{nu}$ mice showed a significant increase $(\mathrm{p}<0.05)$.

Since an increase in the phospholipid content of the BAL fluid is characteristic of silica-treated animals, we also compared the phospholipid content in the BAL fluid from euthymic and athymic mice (fig 6) and found it to be increased in silica-treated euthymic mice. Athymic mutation significantly declined the increase, although a gradual increase was also observed in athymic mice.

\section{Discussion}

In this study we have investigated the role of $T$ lymphocytes in silica-induced pulmonary inflammation and fibrosis by comparing nude athymic and euthymic mice. Histological observations and assessment of lung indices showed that nude athymic mutation protects against silica-induced pulmonary inflammation, suggesting the involvement of $\mathrm{T}$ lymphocytes in the pathogenesis of silicosis. Analyses of BAL fluid further confirmed the modulation of pulmonary inflammation by $T$ lymphocytes since the increase in the protein and phospholipid content of the BAL fluid, a change characteristic of silicosis, was significantly smaller in athymic mice.

Collagen deposition in the lung, evaluated as the hydroxyproline content of the whole lung, ${ }^{17}{ }^{18}$ was significantly reduced in $\mathrm{nu} / \mathrm{nu}$ mice. However, this observation does not simply indicate that athymic mutants are more resistant to pulmonary fibrosis than euthymic mice because athymic animals are smaller in body size (and, accordingly, in lung size) than euthymic animals. In order to eliminate the effect of differences in the body weight and to evaluate the difference in lung collagen deposition more correctly, we have introduced a lung hydroxyproline index (lung hydroxyproline content relative to body weight) following a lung index. ${ }^{33}$ The indices increased gradually after administration of silica, and nu/nu mice showed a significantly smaller increase than $\mathrm{nu} /+$ mice. We therefore conclude that lung collagen deposition is reduced in athymic animals regardless of body weight, and that the mechanism of fibrogenesis in the lung is regulated by $T$ cells.

We have also examined the hydroxyproline content per dry lung weight of the animals as an index of collagen deposition independent of lung size (table 1). Administration of silica caused a definite increase in this parameter on 
day 56 , and the lungs of $\mathrm{nu} / \mathrm{nu}$ mice were more resistant than those of $\mathrm{nu} /+$ mice. This confirms that athymic mutants protect against pulmonary fibrosis elicited by silica, especially in the chronic phase. On the other hand, in earlier phases of silicosis (days 14 and 28) no statistically significant differences in this index were observed between silica-treated and control mice, and in $\mathrm{nu} /+$ mice there was even a tendency to a decrease. This result may be due to the fact that on day 14 there is a considerable increase in lung weight following silica administration which remains more or less constant on days 28 and 56 (fig 2B). This increase in lung weight may be brought about by invasion of inflammatory cells into the interstitium and by the abnormal proliferation of epithelial cells, and the contribution of fibroblast proliferation to the lung weight may not be dominant in the early days after administration of silica. We therefore propose that a lung hydroxyproline index is a more reasonable index for comparing lung collagen deposition between animals of different sizes.

Since the lungs from silica-treated athymic mice developed milder but significant inflammation and collagen deposition, $T$ lymphocytes do not seem to play a primary part in silicosis. Many investigators have suggested that activated macrophages and mediators secreted by them are essential for silica-induced fibrosis. ${ }^{114041} \mathrm{~T}$ lymphocytes may modulate the pathogenic process by modulating macrophage immigration to the lung and/or by changing macrophage function. ${ }^{14}{ }^{29} 42$ In our experiments no significant difference in the number of macrophages in the BAL fluid was observed between athymic mutant and euthymic animals. Similar results have been reported by other investigators. ${ }^{18}$ Hence, it seems unlikely that $\mathrm{T}$ lymphocytes modulate the migration of macrophages to alveolar spaces. On the other hand, since smaller and fewer granulomas were observed in athymic mice, $\mathrm{T}$ lymphocytes may modulate immigration of macrophages/ monocytes into the alveolar septa where fibrogenesis develops. Immigration and retention of activated macrophages in the interstitium may play a key part in pulmonary fibrosis.

Many in vitro experiments have suggested that there is a mutual regulatory mechanism of proliferation and activation between macrophages and $\mathrm{T}$ cells, and that $\mathrm{T}$ lymphocytes modulate the secretory function of macrophages. Various cytokines produced by macrophages and/or T lymphocytes, such as IL-1, IFN $\gamma$, TNF $\alpha$, PDGF $\beta$, have been proposed as key factors in pulmonary inflammation and fibrosis. Although we have not evaluated these mediators, our results seem consistent with the putative mechanisms in which $\mathrm{T}$ lymphocytes regulate silica-induced pulmonary fibrosis by mutually interacting with macrophages.

Neutrophils may also participate in the pathogenesis of fibrosis, ${ }^{83}$ and T lymphocytes may modulate neutrophil function and migration. In our experiments significantly milder BAL fluid neutrophilia was seen in athymic mice than in euthymic mice, except on day 28 . This suggests a mechanism of neutrophil migration regulated by $T$ cells, although the details are unknown at present. It is well documented that activated alveolar macrophages release neutrophil chemotactic factors including IL-8. ${ }^{44}$ Increased expression of the IL-8 gene by alveolar macrophages in idiopathic pulmonary fibrosis has been reported. ${ }^{45}$ Since $\mathrm{T}$ lymphocytes may modulate macrophage functions in silicosis, they may regulate neutrophil migration indirectly by controlling cytokine production in macrophages.

We have previously shown that mast cells are involved in the pathogenesis of silicosis. ${ }^{30} \mathrm{~T}$ cells can regulate the maturation and proliferation of mast cells via production of IL-3 and other cytokines. The possibility exists that mast cells are not fully activated in nude athymic mice and hence the development of the disease is suppressed. However, both in athymic and euthymic mice the numbers of mast cells in the lung parenchyma and the histamine content per lung weight showed a similar increase after silica treatment (data not shown), so mast cell suppression in nude athymic mice - although possible - may not be a primary factor in reducing collagen deposition in silicosis.

Hubbard used the same strains of mice as ours (Balb nu/nu and $\mathrm{nu} /+$ ) and reported that neither $T$ cells nor the cells they influence affected the amount of collagen deposition elicited by silica. ${ }^{18}$ These results seem to conflict with ours; however, there are some differences in the experimental conditions between Hubbard's study and ours which may have led to the discrepancy in the results. In Hubbard's experiments a fixed amount of silica was administered to both $\mathrm{nu} / \mathrm{nu}$ and $\mathrm{nu} /+$ mice regardless of the difference in animal size. Since $\mathrm{nu} / \mathrm{nu}$ mice are considerably smaller in body weight than $\mathrm{nu} /+$ mice, administration of the same amount of silica to both strains might be an overdose for athymic nude mice. Extreme activation of macrophages by an overdose of silica may cause the pathogenic process to get out of lymphocyte control, resulting in surplus fibrosis. In addition, Hubbard compared only the whole lung hydroxyproline content and made no mention of the hydroxyproline content relative to body weight or lung weight. If athymic mice had a similar content of hydroxyproline in the whole lung it would indicate that they had developed more collagen deposition relative to body and lung weight and that the absence of $T$ lymphocytes augmented silica-induced pulmonary fibrosis. We consider that our methods of administering silica (a fixed dose/body weight) and evaluating the degree of pulmonary fibrosis are more feasible for comparing animals of different sizes.

Other factors - for example, age - may have resulted in differences in the response of mice to silica. The mice used in our study were five week old males while those used by Hubbard were 8-12 week old males. The method of administration may also have made a difference; we administered silica transnasally while Hubbard administered it transtracheally. However, we consider our method of administration to be more physiological for an inhalation disease model and less aggressive to animals. 
Allowing for the differences in methodology, the discrepancies between Hubbard's study and ours suggest that the regulation of pulmonary fibrosis by $T$ cells is not simple and is affected by many factors.

In conclusion, nude athymic mice were shown to protect against silica-induced pulmonary inflammation and fibrosis. These results suggest that $T$ lymphocytes control the cellular interactions that lead to a fibrogenetic response of the lung and that agents which suppress $\mathrm{T}$ cell function may be useful in the treatment of pulmonary fibrosis. However, $\mathrm{T}$ cells do not seem to exercise primary control in the pathogenesis of silicosis because reduced but definite collagen deposition was observed in the lungs of athymic mutants. The details of the cellular interactions and cytokines involved require further investigations.

1 Snider GL. Interstitial pulmonary fibrosis - which cell is the culprit? Am Rev Respir Dis 1983;127:535-9.

2 Weissler JC. Idiopathic pulmonary fibrosis: cellular and molecular pathogenesis. Am f Med Sci 1989;297:91-104.

3 Wahl SM, Wahl LM, McCarthy JB. Lymphocyte-mediated activation of fibroblast proliferation and collagen production. F Immunol 1978;121:942-6.

4 Wahl SM, Gately CL. Modulation of fibroblast growth by a lymphokine of human $\mathrm{T}$ cell continuous $\mathrm{T}$ cell line origin. Immunol 1983;130:1226-30.

5 Schrier DJ, Phan SH, McGarry BM. The effects of the nude $(\mathrm{nu} / \mathrm{nu})$ mutation on bleomycin-induced pulmonary fibrosis. A biochemical evaluation. Am Rev Respir Dis 1983;127:614-7.

6 Ekimoto H, Aikawa M, Ohnuki T, Takahashi K, Matsuda A Takita $\mathrm{T}$, et al. Immunological involvement in pulmonary fibrosis induced by peplomycin. I Antibiot (Tokyo) 1985;38:94-8.

7 Seggev JS, Goren MB, Kirkpatrick CH. The pathogenesis of trehalose dimycolate-induced interstitial pneumonitis. III. Evidence for a role for T lymphocytes. Cell Immunol 1984; 85:428-35.

8 Davis GS. Pathogenesis of silicosis: current concepts and hypotheses. Lung 1986;164:139-54.

9 Heppleston AG, Styles JA. Activity of a macrophage factor in collagen formation by silica. Nature 1967;214:521-2.

10 Schmidt JA, Oliver CN, Lepe ZJ, Green I, Gery I Silica-stimulated monocytes release fibroblast proliferation factors identical to interleukin 1. A potential role for interleukin 1 in the pathogenesis of silicosis. 7 Clin Invest 1984; 73:1462-72.

11 Lugano EM, Dauber JH, Elias JA, Bashey RI, Jimenez SA Daniele RP. The regulation of lung fibroblast proliferation by alveolar macrophages in experimental silicosis. Am Rev Respir Dis 1984;129:767-71.

12 Gritter HL, Adamson IY, King GM. Modulation of fibroblast activity by normal and silica-exposed alveolar macrophages. $\mathcal{F}$ Pathol $1986 ; 148: 263-71$.

13 Kumar RK, Li W, O'Grady R. Activation of lymphocytes in the pulmonary inflammatory response to silica. Immuno Invest 1990;19:363-72.

14 Pernis B, Vigliani EC. The role of macrophages and immunocytes in the pathogenesis of pulmonary diseases due to mineral dusts. $A m \mathcal{F}$ Ind Med 1982;3:133-7.

15 Kumar RK. Quantitative immunohistologic assessment of lymphocyte populations in the pulmonary inflammatory response to intratracheal silica. Am $\mathcal{F}$ Pathol 1989;135:60514.

16 Struhar D, Harbeck RJ, Mason RJ. Lymphocyte population in lung tissue, bronchoalveolar lavage fluid, and peripheral blood in rats at various times during the devel
silicosis. Am Rev Respir Dis 1989;139:28-32.

17 Callis AH, Lucas DO. Modulation by T cells of pulmonary inflammation and fibrosis in an experimental model of silicosis. Chest 1986;89:169-70S

18 Hubbard AK. Role for T lymphocytes in silica-induced pulmonary inflammation. Lab Invest 1989;61:46-52.

19 Kimura R, Hu H, Stein SJ. Delayed-type hypersensitivity responses regulate collagen deposition in the lung. Immunology 1992;77:550-5.

20 Holgate ST, Djukanovic R, Howarth PH, Montefort S, Roche W. The $T$ cell and the airway's fibrotic response in asthma. Chest 1993;103:125-8S
21 Mizel SB, Oppenheim JJ, Rosenstreich DL. Characterization of lymphocyte-activating factor (LAF) produced by the macrophage cell line, P388D1. I. Enhancement of $\mathrm{LAF}$ production by activated T lymphocytes. $f$ Immunol 1978;120:1497-503

22 Farrar WL, Mizel SB, Farrar JJ. Participation of lymphocyte activating factor (interleukin 1) in the induction of cytotoxic $T$ cell responses. 7 Immunol 1980;124:1371-7.

23 Hunninghake GW, Glazier AJ, Monick MM, Dinarello CA. Interleukin-1 is a chemotactic factor for human T-lymphocytes. Am Rev Respir Dis 1987;135:66-71.

24 O'Garra A. Interleukins and the immune system 2. Lancet 1989;i:1003-5.

25 Shaw RJ, Benedict SH, Clark RA, King TE. Pathogenesis of pulmonary fibrosis in interstitial lung disease. Alveolar macrophage PDGF(B) gene activation and up-regulation by interferon gamma. Am Rev Respir Dis 1991;143:16773

$26 \mathrm{Li} \mathrm{W,} \mathrm{Kumar} \mathrm{RK,} \mathrm{O'Grady} \mathrm{R,} \mathrm{Velan} \mathrm{GM.} \mathrm{Role} \mathrm{of}$ lymphocytes in silicosis: regulation of secretion of macrophage-derived mitogenic activity for fibroblasts. Int f Exp Pathol 1992;73:793-800.

27 Heppeleston AG, Wright NA, Stewart JA. Experimental alveolar lipo-proteinosis following inhalation of silica. $\mathcal{F}$ Pathol 1970;101:293-307.

28 Grunspan M, Antweiler H, Dehnen W. Effect of silica on phospholipids in the rat lung. Brf Ind Med 1973;30:74-7.

29 Dethloff LA, Gilmore LB, Brody AR, Hook GER. Induction of intra- and extra-cellular phospholipids in the lungs of rats exposed to silica. Biochem 7 1986;233:111-8.

30 Suzuki N, Horiuchi T, Ohta K, Yamaguchi M, Ueda T, Takizawa $\mathrm{H}$, et al. Mast cells are essential for the full development of silica-induced pulmonary inflammation: a study with mast cell-deficient mice. Am $\mathcal{F}$ Respir Cell Mol Biol 1993;9:475-83.

31 Rossi GA, Szapiel S, Ferrans VJ, Crystal RG. Susceptibility to experimental interstitial lung disease is modified by immune- and non-immune-related genes. Am Rev Respir Dis 1987;135:448-55.

32 Takizawa H, Ohta K, Hirai K, Misaki Y, Horiuchi T, Kobayashi $\mathrm{N}$, et al. Mast cells are important in the development of hypersensitivity pneumonitis. A study with mast-celldeficient mice. F Immunol 1989;143:1982-8.

33 Allen EM, Moore VL, Stevens JO. Strain variation in BCGinduced chronic pulmonary inflammation in mice. I. Basic model and possible genetic control by non- $\mathrm{H}-2$ genes. $\mathcal{F}$ Immunol 1977;119:343-7.

34 Callis AH, Sohnle PG, Mandel GS, Wiessner J, Mandel NS. Kinetics of inflammatory and fibrotic pulmonary changes in a murine model of silicosis. $7 \mathrm{Lab}$ Clin Med 1985;105:547-53.

35 Takizawa $\mathrm{H}$, Ohta $\mathrm{K}$, Horiuchi $\mathrm{T}$, Suzuki $\mathrm{N}$, Ueda $\mathrm{T}$, Yamaguchi $\mathrm{M}$, et al. Hypersensitivity pneumonitis in Yamaguchi $\mathrm{M}$, et al. Hypersensitivity pneumonitis in ency. Am Rev Respir Dis 1992;146:479-84.

36 Woessner JF. Determination of hydroxyproline in connective tissues. In: Hall DA, ed. The methodology of connective tissue research. 1st edn. Oxford: Joynson-Bruvvers Ltd, 1976:227-33.

37 Reynolds HY, Fulmer JD, Kazmierowski JA, Roberts WC, Frank MM, Crystal RG. Analysis of cellular and protein content of broncho-alveolar lavage fluid from patients with idiopathic pulmonary fibrosis and chronic hypersensitivity pneumonitis. $\mathcal{F}$ Clin Invest 1977;59:165-75.

38 Bligh EG, Dyer WJ. A rapid method of total lipid extraction and purification. Can $\mathcal{F}$ Biochem Physiol 1959;37:911-7.

39 Rouser GA, Siakotos N, Fleischer S. Quantitative analysis of phospholipids by thin layer chromatography and phosphorus analysis of spot. Lipids 1966;1:85-6.

40 Piguet PF, Collart MA, Grau GE, Sappino AP, Vassalli P. Requirement of tumour necrosis factor for development of silica-induced pulmonary fibrosis. Nature 1990; 344:245-7.

41 Bitterman PB, Rennard SI, Hunninghake GW, Crystal RG. Human alveolar macrophage growth factor for fibroblasts. Regulation and partial characterization. $\mathcal{F}$ Clin Invest 1982; 70:806-22.

42 Kovacs EJ, Kelley J. Lymphokine regulation of macrophagederived growth factor secretion following pulmonary injury. Am 7 Pathol 1980;121:261-8.

43 Adamson IY, Bowden DH. Role of polymorphonuclearleukocytes in silica-induced pulmonary fibrosis. Am $\mathcal{f}$ Pathol cytes in silica-in

44 Strieter RM, Chensue SW, Basha MA, Standiford TJ, Lynch JP, Baggiolini M, et al. Human alveolar macrophage gene expression of interleukin- 8 by tumor necrosis factoralpha, lipopolysaccharide, and interleukin-1 beta. $A m \mathcal{F}$ Respir Cell Mol Biol 1990;2:321-6.

45 Carre PC, Mortenson RL, King TE, Noble PW, Sable CL, Riches DW. Increased expression of the interleukin-8 gene by alveolar macrophages in idiopathic pulmonary fibrosis. A potential mechanism for the recruitment and activation of neutrophils in lung fibrosis. 7 Clin Invest 1991;88:1802-10. 